\title{
RSP Revisitada A funcionária pública sob a Constituição de 1937
}

Amelia Duarte

Texto publicado na RSP, n 4, Março de 1938

\begin{abstract}
Na primeira edição de 2010 da Revista do Serviço Público, a RSP Revisitada relembra as lutas, ao longo da história do país, pela garantia dos direitos civis das mulheres brasileiras, com a publicação deste artigo.

A trajetória profissional de Amélia Duarte é exemplo do processo de afirmação da cidadania das brasileiras. Em 1936, ela rompeu paradigmas ao ingressar no Ministério Público Federal, tornando-se a primeira mulher nos quadros da instituição. Seguida do direito ao voto, obtido em 1932, a conquista de Amélia Duarte foi um símbolo de que as brasileiras estavam, sim, preparadas para exercer cargos mais elevados na República.
\end{abstract}

A Revolução de 30 fixa, na história da evolução social brasileira, um momento de grande significação. A época que imediatamente a precedeu pode ser caracterizada pela frase de um dos últimos chefes de Estado do Brasil, ao definir como caso de polícia a questão social, quando as legislações da generalidade dos povos cultos a ela já dedicavam cuidados especiais.

"Sem nos determos sôbre a lista habitual das liberdades individuais, reproduzidas na maioria das Constituições novas - diz o notável professor MirkineGuetzévitch, em estudo sôbre as Constituições de após guerra - não assinalaremos aquí sinão as novas tendências, as novas concepções sociais que se expressam nessas Constituições". (As novas tendências do Direito Constitucional, trad. de Candido Motta Filho, 1933, pag. 79).

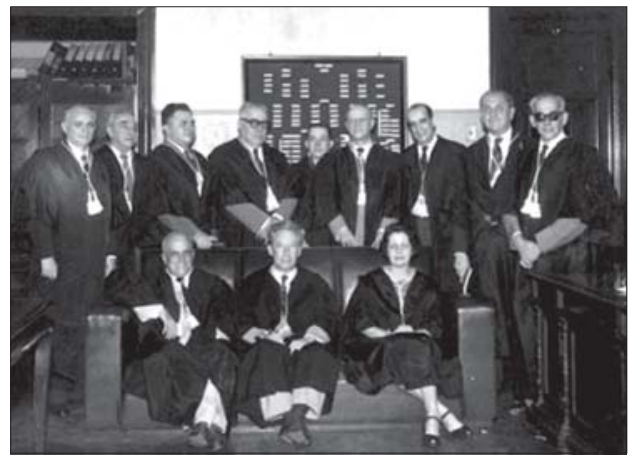


A reforma da Constituição brasileira de 91, em 1926, nenhuma modificação a propósito introduziu no país, resultado êsse que não se deve atribuir tão somente à ausência de partidos de esquerda com representação na Assembléia Legislativa, pois, como assinala o referido Mirkine: "a aparição dos direitos sociais em algumas declarações novas foi devida à influência dos socialistas (Alemanha, por exemplo). Mas, nas Assembléias constituintes em que o papel dos socialistas era modesto ou mesmo insignificante, os direitos sociais entraram nos textos constitucionais" (ibidem, pag. 150).

Dessa situação, que registramos apenas, resultou, indubitavelmente, expandirem-se todos os anseios recalcados, lídimos ou não, na segunda Constituinte Republicana, que foi da Revolução de 30 uma consequência.

Por isso mesmo, o estatuto político de 34 , ao contrário do de 91, mais preocupado, na implantação da forma federativa no país, em bem fixar as atribuições da União e dos Estados, não modelou tão somente para o corpo político nacional um figurino de linhas gerais e, sim, desceu por vezes a minudências até então a cargo de leis ordinárias.

Dess'arte, aliás a exemplo da Constituição alemã, dedicou ao funcionário público cuidados especiais de proteção aos seus particulares interêsses e, mui especialmente, à mulher garantiu, como norma geral, $\mathrm{O}$ direito de acesso a todos os cargos públicos, qualquer que fôsse o seu estado civil.

O substitutivo, apresentado à Comissão constitucional pelos relatores do capítulo da Constituição: "Dos funcionários públicos", aо dispositivo (art. 90); “Os cargos públicos são acessivieis a todos os brasileiros, observadas as condiçoes que a lei estatuir. Excepcionalmente, um extrangeiro poderá ser contratado para desempenho de função pública", estava assim justificado:
"ÊEsse artigo, em sua primeira parte, reproduz o artigo 73 da Constituição de 1891. Já a Constituição do Império preceituava. no art. 179 . $\mathrm{n}^{\mathrm{o}} 14$, que todo cidadão podia ser admitido aos cargos públicos. sem outra diferença que não fôsse a de seus talentos e virtudes. Ao dispositivo do citado artigo 90 que consagra o princípio salutar de que os cargos públicos não podem constituir privilégios de classes ou de pessoas, julgamos necessário acrescentar a cláusula - sem distinção de sexo ou de estado civil. Quanto à segunda parte do art. 90, preferimos a disposição contida na emenda $\mathrm{n}^{\circ}$ 30-B. substituindo na mesma a expressão - nimiamente técnica - pela rigorosamente técnica" (Anais da Assembléia Nacional Constituinte, vol. X, pago 421, 1936).

As razões por que considerava necessário acrescentar - sem distinção de sexo ou de estado civil - ao referido preceito constitucional, não nas deu o legislador.

Teremos assim, para fundamentar as conclusões a que pretendemos chegar neste estudo, de - em rápido bosquejo apreciar o ambiente brasileiro, com relação à condição da mulher.

Não será, assim, sem oportunidade, lembrarmos que o individualismo da Constituição de 91 permitira ao legislador ordinário usar e abusar das suas atribuições com respeito à situação jurídica da mulher. Pela lei eleitoral, negara-lhe êle, com excepção do Estado do Rio Grande do Norte, o exercício do voto, a despeito do princípio constitucional de que eleitores eram os cidadãos maiores de 21 anos, alistados na forma da lei.

No nosso velho Código Comercial e em leis posteriores, se afirmou sempre o princípio proibitivo de desempenho, pelas mulheres, dos ofícios de corretor e leiloeiro.

Em Estados do Norte, imbuído por certo o legislador de uma concepção 
errada da vida, impusera-se à mulher a perda do cargo público que exercesse, pelo efeito de contrair matrimônio.

Para a modificação dêsse estado de cousas, pouco conseguira até então, ora isoladamente, ora com função associativa, o esfôrço feminino no Brasil, o qual ia sempre de encontro à barreira de tolos preconceitos, que se resumiam, no caso, no receio infundado de perigo de subversão da moral social.

A Revolução de 30 implantou a respeito uma mentalidade inteiramente nova no Brasil. Sentira ela de perto os anseios da mulher brasileira, de renovação do nosso ambiente político; tivera-a lado a lado na cruzada das idéias novas e, por isso mesmo, lhe premiaram a cooperação os vencedores. Ao ser, algum tempo depois, promulgado o Código Eleitoral, foi à mulher atribuído o direito de votar e ser votada. Iniciava-se assim uma época inteiramente nova no país e com tal fôrça de manifestação que - a despeito da ascendência do marido sôbre a mulher na sociedade conjugal, considerada pelo Código Civil relativamente incapaz para a prática de certos atos da vida - não hesitaram os Tribunais Eleitorais, em várias decisões, em julgar desnecessária a outorga marital para que a mulher casada pudesse cumprir o seu dever cívico.

Mas uma lei ordinária, como o Código Eleitoral, não oferecia as mesmas garantias de estabilidade que um preceito constitucional, e, daí, ao se instalar a segunda Assembléia Constituinte Republicana, o cuidado da "Federação Brasileira pelo Progresso Feminino" - entidade que, com filiais em todos os Estados, chefiara destemerosamente, desde longos anos, a campanha de defesa dos direitos da mulher no país - em ver as suas aspirações básicas incorporadas ao estatuto político que aquela Assembléia elaboraria.
Não contava aí, porém, a "Federação" com uma autêntica representante das suas hostes e, por isso mesmo, a sua ação não se poderia fazer sentir diretamente no plenário da Assembléia e sim na arregimentação de partidários isolados.

Preparadas por ela as emendas que consubstanciavam os pontos básicos do seu programa, encaminhou-as a amigos da sua causa, que, por sua vez, as incorporaram à Constituição de 34.

A essa altura, cabe-nos, a bem da verdade e da justiça, salientar aquí o apôio que sempre prestou a essa associação o presidente Getúlio Vargas, a quem as mulheres no Brasil devem, em grande parte, a sua nova condição jurídica.

Mas, dentre as emendas a que nos referimos, achava-se a que interditava à lei ordinária o afastamento da mulher de qualquer cargo público em razão do sexo ou do estado civil, que a Constituição de 34 consagrou. E a despeito do seu dispositivo (art. 170), que conferia ao Poder Legislativo Nacional a atribuição de elaborar o "Estatuto do Funcionário Público", as Constituições dos Estados, talvez com exclusão apenas de Minas, Paraná, Pernambuco e Pará, todas, expressamente, acolheram aquele princípio, cuja vigência entre nós foi, aliás, de salutar efeito. Basta dizer que nesse decurso de tempo, para postos de acentuado destaque e responsabilidade, foram várias mulheres nomeadas.

Assim, ao lado das oficiais de gabinete de Ministros e da Presidência da República, figuravam as promotoras públicas, as consulezas e as professoras de escolas superiores.

Foi nesse ambiente, inteiramente favorável ao elemento feminino, que entrou a vigorar a Constituição de 37.

Lê-se no seu artigo 122, nํㅜㅇ: “os cargos públicos são igualmente acessíveis 
a todos os brasileiros, observadas as condições de capacidade prescritas nas leis e regulamentos".

Que ela admite a mulher funcionária, dúvida alguma pode subsistir. Bastará atender à letra $b$ do seu artigo 156: “os funcionários terão direito a férias anuais, sem descontos, e a gestante a tres mêses de licença com vencimentos integrais".

Quais, porém, as condições de capacidade, a que alude a Constituição e que o legislador ordinário poderá prescrever?

Parece-nos que tão somente as de ordem intelectual, demonstradas em concurso de provas ou de títulos (art. 156, letra b) e não de forma a especialmente atingir à mulher.

Muito se falou que, ao regulamentar o dispositivo constitucional que veda a acumulação de cargos públicos, o atual Govêrno afastaria das repartições públicas o elemento feminino, com excepção apenas das mulheres que provassem ser, na família, o seu arrimo.

De passagem, focalizemos a dificuldade de ser essa situação apurada, pela delicadeza de uma investigação em tôrno da vida íntima das famílias, para registrarmos com prazer que o decreto-lei sôbre as acumulações não consagrou tal injustiça, que seria mesmo - porque não dizer? uma anomalia ao liberalismo da nossa legislação, no tocante ao exercício, pelo indivíduo, de atividades lícitas.
Muito ao contrário, instaurado o novo regime, o elemento feminino continuou a ser aproveitado para o preenchimento de vagas nos quadros da administração pública. A propósito, vale a pena citar uma recentíssima decisão do ilustre general Eurico Dutra, consoante notícia dos jornais, indeferindo o requerimento de um senhor que desejava fôsse tornada sem efeito a nomeação de sua companheira para um cargo do Ministério da Guerra, depois de um concurso de provas, no qual a candidata se classificara em $1^{\circ}$ lugar.

Por tais fundamentos, que preconizam já o espírito que anima o Estado Novo a respeito da mulher que trabalha, não hesitamos em afirmar que, existindo as leis em função histórica como corolário de necessidades ambientes, o fato de expressamente não inserir a Constituição de 37 um dispositivo que especialmente salvaguardasse a situação da mulher, quanto ao acesso a todos os cargos públicos, só pode ser atribuído à circunstância de ser ela a mais promissora, quando aquele estatuto político foi promulgado.

A nosso ver, pois, a própria mulher, pela sua inteligência, inteireza de caráter e tino administrativo, terá presentemente muito mais a fazer em benefício de sua causa do que um preceito legal. E que a respeito não se trata mais entre nós de uma época de reivindicações e sim da consolidação de uma situação conquistada. 